\title{
Introduction: New Perspectives on Health, Disability, Welfare and the Labour Market
}

\author{
Colin Lindsay, Bent Greve, Ignazio Cabras, \\ Nick Ellison and Steve Kellett
}

\section{Introduction}

More than 2.4 million people of working age in the UK are out of work and claiming 'incapacity' or disability benefits (DBs). Reducing the high levels of benefit claiming among those with health limitations and disabilities has been a priority for successive governments (Lindsay and Houston 2013). Other countries of the Organisation for Economic Co-operation and Development (OECD), ranging from Sweden, with its 'social democratic' welfare state (Hagelund and Bryngelson 2014), to the 'liberal' USA also report high rates of disability claiming, and have similarly prioritized measures to bring down welfare rolls (Milligan 2012). Given this context, policy debates have focused on both reforms to the administration of DBs and the content of targeted activation (Bannink 2014).

Recent policy responses in the UK have taken the form of measures to restrict access to welfare benefits and impose increased compulsory 'workrelated activity' on claimants. However, current policy arguably fails to reflect the evidence that people on long-term DBs face a complex combination of barriers to work and social inclusion. The evidence points to a multi-dimensional form of disadvantage, requiring a holistic, joined-up policy response - claimants may struggle to manage a range of disabilities and health conditions (with mental health problems widespread); many report gaps in employability and skills; and, crucially, claiming is spatially concentrated in communities characterized by poor health and labour markets that have fewer (and fewer high quality) job opportunities. Many of these challenges are present in other European and OECD welfare states, where there are similar tensions between activation policies that seek to drive sick and disabled people off benefits and into work, and the challenges faced by these people to manage conditions and sustain their position in the labour market.

There is a need for continuing inter-disciplinary research on the nature of the 'disability benefits problem' and the efficacy of current policy solutions 
and public services. This Special Issue brings together researchers who seek to explore the distinctive, yet interrelated, elements of the problems faced by disability claimants, and evaluate related policies and services. The Special Issue is co-edited by an inter-disciplinary team drawn from the fields of social policy, economics, sociology and clinical psychology. A seminar series supported by the White Rose University Consortium allowed many of the authors to share early versions of their articles.

\section{Content of the Special Issue}

All of articles that follow connect with key issues around the complex combination of health, employability, workplace and labour market-related factors that explain DB claiming in disadvantaged areas and among vulnerable groups. The Special Issue opens with a review of evidence conducted by the co-editors. We present the most up-to-date and robust evidence on the nature of the DB problem in the UK. While drawing upon frameworks presented by previous studies (Beatty et al. 2009; Lindsay and Houston 2011, 2013), we also identify important new and emerging evidence, for example in relation the impact of poor quality jobs on working-age health, and how labour market casualization has contributed to DB claiming. The other contribution of this first article is a comparative analysis of the disability activation and welfare reform agenda in a very different welfare state - Denmark. Here, we acknowledge that, despite a greater readiness to intervene in the workplace (through initiatives such as the flex-jobs programme), policymakers have similarly struggled to arrive at solutions that address the disadvantage faced by disabled people. We conclude that more radical solutions may be required to deliver genuine equality of opportunity in the mainstream labour market, and to stimulate sufficient labour demand in regions and welfare states where there are simply too few decent jobs.

The next three articles in this Special Issue analyze aspects of the 'DB problem' from a range of theoretical and disciplinary starting points. Christina Beatty and Steve Fothergill take a long-view of the rise in disability claimant numbers in the UK since the 1970s, and conclude that spatial concentrations of health and disability-related worklessness have proved largely impervious to successive waves of welfare reform. However, they also note that increased conditionality in access to benefits (the centrepiece of the current UK policy agenda) risks driving the most vulnerable out of the system, resulting in increased social risk. Only policies designed to address ill-health and disability, combined with demand-side labour market interventions, can help to empower DB claimants to progress towards meaningful work.

Ben Baumberg presents in-depth, qualitative data to demonstrate how 
lower skilled workers in disadvantaged labour markets are less able to access the kind of workplace adjustments that might otherwise allow them to cope with health or disability-related limitations. Baumberg's research thus reiterates the multi-dimensional character of the potential barriers faced by DB claimants, which are rooted not only in health limitations and disability, but also structural labour market and workplace factors. Kayleigh Garthwaite also draws on qualitative research, exploring experiences of poverty, social isolation and stigma among the DB claimant group - a grim reality at odds with the popular mythology of a feckless underclass choosing life on benefits. Will Whittaker and Matt Sutton provide further quantitative evidence demonstrating that the health limitations of DB claimants are real. Whittaker's and Sutton's longitudinal analysis of British Household Panel Survey data highlights the particular importance of mental ill-health in explaining high rates of DB claiming over time.

The final three articles return to a more explicit focus on evaluating and informing current policy. First, Fiona Purdie and Steve Kellett present the results of extensive survey research with DB claimants participating in condition management programmes designed and delivered by health professionals. They identify well-being and employability benefits for many of those participating, reinforcing the message that health-related support should be central to policies to address the DB problem. Purdie and Kellett also, however, acknowledge differences in the outcomes achieved for sub-groups among those on DBs, arguing for further research to inform a broader range of health services targeting people on working-age benefits. Within the UK policy context, we appear to be some way off the establishment of such holistic and broad-based health interventions. Indeed, the article by Jenny CeoltaSmith, Sarah Salway and Angela Mary Tod on the Work Programme in the UK suggests that access to health-related support is likely to be partial and unequal among the DB claimant group. Lastly, the article by Mike Danson, Ailsa McKay and Willie Sullivan offers a macro-level, comparative perspective on worklessness and inequality. This final article identifies lessons from some of Europe's more equal societies and argues for a fundamental recalibration of welfare and economic policies in the UK to address entrenched inequalities. It is an eloquent and impassioned argument reflecting the commitment to policies for a fairer society that defined the career of our late and greatly respected colleague (and article co-author) Professor Ailsa McKay.

The UK, like many other welfare states, faces a continuing problem of high levels of disability claiming. In the longer term, policymakers will also be required to respond to the challenge of helping an ageing labour force to work for longer, which will inevitably mean managing health conditions and disabilities in the workplace. Current policy in the UK focuses almost entirely on 
restricting access to benefits and imposing work-first activation in order to address imagined behavioural deficits among claimants. These policies may achieve the short-term goal of driving some vulnerable people out of the welfare system, but there is little evidence that they can provide routes into sustainable employment. A new policy agenda is required, which addresses the complex combination of health, employability, workplace and labour market-related factors that explain the UK's DB problem. Our duty as social policy researchers is to marshal the evidence from across disciplines in the hope of informing appropriate policies. This Special Issue seeks to make a small contribution to that shared goal.

\section{References}

Bannink, D. (2014), Social policy from Olson to Ostrom: a case study of Dutch disability insurance, Social Policy \& Administration, 48, 3: 279-99.

Beatty, C., Fothergill, S., Houston, D., Powell, R. and Sissons, P. (2009), A gendered theory of employment, unemployment and sickness, Environment and Planning $C$ : Government and Policy, 27, 6:958-74.

Hagelund, A. and Bryngelson, A. (2014), Change and resilience in welfare state policy: the politics of sickness insurance in Norway and Sweden, Social Policy \& Administration, 48, 3: 300-18.

Lindsay, C. and Houston, D. (2011), Fit for purpose? Welfare reform and challenges for health and labour market policy in the UK, Environment and Planning A, 43, 3: 703-21.

Lindsay, C. and Houston, D. (2013), Disability Benefits, Welfare Reform and Employment Policy, Basingstoke: Palgrave Macmillan.

Milligan, K. (2012), The long-run growth of disability insurance in the United States. In D. Wise (ed.), Social Security Programs and Retirement Around the World, Chicago, IL: University of Chicago Press, pp. 359-89. 